\title{
Design of Experiments for Critical Material Attributes Assessment of Linagliptin and Metformin Fixed-dose Combination Tablets
}

\author{
Kang Min Kim \\ Department of Pharmaceutical Science and Technology, Kyungsung University, Busan, SOUTH KOREA.
}

\begin{abstract}
Aim of work: This study aimed to determine the amount of excipients in the critical material attributes of linagliptin and metformin sustained release (SR) fixed-dose combination (FDC) tablets using design of experiments (DoE). Methods: A $2^{3}$ full factorial design with three center points was performed. For the screening of excipients, 3-factor responses (mannitol, sodium starch glycolate and pregelatinized starch for linagliptin; hydroxypropyl methylcellulose, sodium carboxymethyl cellulose (CMC) and hydroxypropyl cellulose for metformin), 2-levels and 1-center $(n=3)$ point with three responses (friability, assay and dissolution) were applied to the DoE batch using Design-Expert. Results: Most excipients were an important factor in the friability, assay and dissolution results $(P<0.05)$. In the screening of excipients, mannitol $(40-60 \mathrm{mg})$ and pregelatinized starch $(40-60 \mathrm{mg})$ with sodium starch glycolate $(5 \mathrm{mg})$ for linagliptin and hydroxypropyl cellulose (15-23 $\mathrm{mg}$ ) and CMC (40-55 $\mathrm{mg}$ ) with hydroxypropyl methylcellulose $(260 \mathrm{mg}$ ) for metformin were optimal. Conclusion: In summary, selection for the amount of excipients can be defined through levels of risk based on three responses. It can be concluded that the ranges of excipients leading to high quality (low friability and optimal ranges of assay and dissolution) for the screening of excipients were successfully observed by the DoE approach.
\end{abstract}

Key words: Critical material attributes, Design of experiments, Linagliptin, Metformin, Quality by design.

\section{INTRODUCTION}

Linagliptin, called 'Trajenta' ${ }^{\circledR}$ (reference listed drug; RLD), is administered as an adjunct to diet and exercise therapy to improve blood sugar regulation in insulinnon-dependent (type 2) diabetics. ${ }^{1,2}$ If sufficient blood sugar regulation cannot be performed either by linagliptin or metformin therapy, Trajenta ${ }^{\circledR}$ should be administered as a daily treatment. The recommended daily dose is $5 \mathrm{mg}$, regardless of diet. ${ }^{1}$ Linagliptin, a dipeptidyl peptidase- 4 inhibitor, is used as a type 2 diabetes medicine like sitagliptin, saxagliptin and alogliptin. Linagliptin produces insulin and reduces pancreatic glucagon. ${ }^{3}$ After a single oral administration, linagliptin reaches the maximum plasma concentration $\left(\mathrm{C}_{\text {max }}\right)$ after approximately 1.5 $\mathrm{h}$ and has an elimination half-life of $<24 \mathrm{~h}$ and $<30 \%$ bioavailability. ${ }^{4}$

Metformin, called 'Glucophage ${ }^{\circledR}$ XR' (RLD), is a drug that improves blood sugar regulation in adult type 2 diabetics. ${ }^{5}$ In the case of medical treatment, a minimum effective dose should be administered for this drug which is similar to sulfonylurea and insulin. The initial dose is $500 \mathrm{mg}$ per day and can be gradually increased up to $2000 \mathrm{mg}$ depending on blood sugar levels. ${ }^{5}$ Metformin, a biguanide antihyperglycemic agent, is used in the treatment of type 2 diabetes. Metformin decreases the production of glucose in the liver and increases insulin sensitivity in tissues. ${ }^{6}$ After single oral administration, metformin
Submission Date: 02-11-2020; Revision Date: 17-02-2021; Accepted Date: 18-05-2021

DOI: 10.5530/ijper.55.3.142 Correspondence: Prof. Kang Min Kim

Department of Pharmaceutical Science and Technology, Kyungsung University, Busan, SOUTH KOREA.

Phone: +82-10-3266-2687

Email id: kimkmks@ks.ac.kr

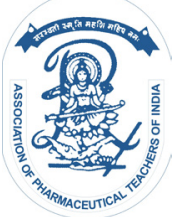

www.ijper.org 
reaches maximum plasma concentration $\left(\mathrm{C}_{\max }\right)$ after approximately $2.5 \mathrm{~h}$ and has an elimination half-life of 4.0-8.7 $\mathrm{h}$ and $50-60 \%$ bioavailability. ${ }^{7,8}$

Bi-layer tablets with FDCs generally comprise additives with the active pharmaceutical ingredient to produce a robust formulation. Formulation development of bi-layer tablets within the manufacturing process requires consistent consideration of the intended quality of the drugs within the critical quality attributes (CQAs). ${ }^{9} 10$ Based on the compatibility test results and prototype composition of formulations, the Food and Drug Administration and Ministry of Food and Drug Safety are supposed to regulate appropriate additives in the formulation to identify quality assurances. ${ }^{11}$ In addition, the physical and chemical interaction study between drugs and additives should also be considered for the selection of additives in the formulation. The International Council for Harmonization of Technical Requirements for Pharmaceuticals for Human Use (ICH) Q8(R2) pharmaceutical development guidelines regulate the formulation and manufacturing process for robust drug development through the quality by design (QbD) approach. ${ }^{11}$

The purpose of this study was to investigate the robust composition of important additives used in the bi-layered tablet development of linagliptin and metformin sustained release (SR) FDC through DoE analysis. Based on the composition of the RLD, mannitol, pregelatinized starch and sodium starch glycolate for the linagliptin layer and hydroxypropyl methylcellulose, CMC and hydroxypropyl cellulose for the metformin layer were adopted as the additives.

\section{MATERIALS AND METHODS}

\section{Samples and reagents}

Linagliptin (99.4\% purity) was supplied by Ruyuan Hec Pharma Co., Ltd. (Guangdong, China). Metformin hydrochloride ( $99.7 \%$ purity) was supplied by Wanbury Limited Co., Ltd. (Maharashtra, India). The excipients mannitol (D-mannitol), pregelatinized starch (Starcap ${ }^{\circledR}$ 1500), lysine, silicone dioxide, sodium starch glycolate, magnesium sterate, hydroxypropyl methylcellulose (Benecel $\left.^{\mathrm{TM}} \mathrm{K} 200 \mathrm{M}\right), \mathrm{CMC}$ and hydroxypropyl cellulose (Klucel $^{\circledR}$ H type) were purchased from Hwawon Pharmaceuticals, Masung and Colorcon Co., Ltd (Seoul, Korea). All reagents were of HPLC grade and purchased from Merck (Whitehouse Station, NJ, USA). The reference formulation of linagliptin was Trajenta ${ }^{\circledR} 5$ mg (Boehringer Ingelheim Co., Ltd., Germany) and that of metformin was Glucophage ${ }^{\circledR}$ XR $1000 \mathrm{mg}$ (MSD Korea Co., Ltd., Korea).

\section{Preparation of linagliptin and metformin FDC tablets}

Preparation of linagliptin and metformin SR prototype FDC tablets: SR FDC tablets of linagliptin and metformin were prepared by wet granulation using a high-speed mixer (Nara Machinery Co., Ltd., NMG-1L, Tokyo, Japan). The linagliptin layer (linagliptin $5 \mathrm{mg}$, mannitol $40 \mathrm{mg}$, lysine $5 \mathrm{mg}$ and pregelatinized starch $44 \mathrm{mg}$ per tablet) and metformin layer (metformin 1,000 $\mathrm{mg}$, CMC $50 \mathrm{mg}$ and hydroxypropyl cellulose $20 \mathrm{mg}$ per tablet) were mixed and granulated with an appropriate amount of water in a high-speed mixer (Nara Machinery Co., Ltd., NMG-1L, Tokyo, Japan). Wet granules were passed through a $1.5 \mathrm{~mm}$ screen. The screened granules were directly dried at $60^{\circ} \mathrm{C}$. The dried granulates were screened using a $600 \mu \mathrm{m}$ screen (K50, Eur-Asia, China) at 1,000 rpm. Then, silicon dioxide, sodium starch glycolate and magnesium stearate for the linagliptin layer and hydroxypropyl methylcellulose, silicon dioxide and magnesium stearate for the metformin layer were mixed using a double cone blender (HS-DCM-10, Hansung F\&C Co., Korea) for 200 revolutions at $10 \mathrm{rpm}$. The tableting was performed by compressing a total weight of $1,450 \mathrm{mg}$ under a compression force of $13 \mathrm{kP}$ using a Piccola Nova tablet press (AutoTab 200TR, Ichihashiseiki Co., Ltd., Japan).

\section{Product attribute study}

The initial risk assessment of critical material attributes (CMAs) for linagliptin and metformin SR FDC tablets indicated that assay and dissolution rates were at a high risk of being affected by the CMA study for additives and composition decision. Tables 1 and 2 summarize the risk assessment of the effects of CMAs (mannitol, sodium starch glycolate and pregelatinized starch for linagliptin and hydroxypropyl methylcellulose, CMC and hydroxypropyl cellulose for metformin), affecting the CQAs such as assay, friability and dissolution. ${ }^{12} \mathrm{~A} 2^{3}$ full factorial design for the DoE study was used in this study. As shown in Tables 3 and 4, eleven batch formulations each of linagliptin and metformin were estimated for the DoE study with center points using Design-Expert, version 12.0.3.0 (Stat-Ease Inc., Minneapolis, MN, USA) to identify the relationship between factors and CQAs.

\section{Friability test}

A friability tester (Friability Tester FR 2000, Copley, United Kingdom) was used to evaluate friability. Ten tablets were measured before and after the loss of mass at a speed of $25 \mathrm{rpm}$ for 4 min. ${ }^{13}$ 


\begin{tabular}{|c|c|c|c|c|c|}
\hline \multirow{2}{*}{\multicolumn{3}{|c|}{ Factors: Material Attribute }} & \multicolumn{3}{|c|}{ Levels } \\
\hline & & & -1 & 0 & +1 \\
\hline$A$ & \multicolumn{2}{|c|}{ Mannitol (mg) } & 20 & 40 & 60 \\
\hline B & \multicolumn{2}{|c|}{ Pregelatinized starch $(\mathrm{mg})$} & 20 & 40 & 60 \\
\hline C & \multicolumn{2}{|c|}{ Sodium starch glycolate $(\mathrm{mg})$} & 1 & 5 & 9 \\
\hline \multicolumn{2}{|c|}{ Responses } & Goal & \multicolumn{3}{|c|}{ Acceptable ranges } \\
\hline$Y_{1}$ & Friability (\%) & Minimize & \multicolumn{3}{|c|}{$\leq 1 \%$} \\
\hline$Y_{2}$ & $\begin{array}{l}\text { Dissolution similarity } \\
\text { of linagliptin ( } \mathrm{f} 2 \text { ) }\end{array}$ & Maximize & \multicolumn{3}{|c|}{$\geq 55$ (f2) } \\
\hline$Y_{3}$ & $\begin{array}{l}\text { Assay of linagliptin } \\
\qquad(\% \mathrm{w} / \mathrm{w})\end{array}$ & In range & \multicolumn{3}{|c|}{$95.0 \% \mathrm{nY}_{3} \leq 105.0 \%$} \\
\hline
\end{tabular}

\begin{tabular}{|c|c|c|c|c|}
\hline \multirow{2}{*}{\multicolumn{2}{|c|}{ Factors: Material Attribute }} & \multicolumn{3}{|c|}{ Levels } \\
\hline & & \multirow{2}{*}{$\begin{array}{c}-1 \\
220\end{array}$} & \multirow{2}{*}{$\begin{array}{c}0 \\
260\end{array}$} & \multirow{2}{*}{$\begin{array}{l}+1 \\
300\end{array}$} \\
\hline A & $\begin{array}{l}\text { Hydroxypropyl } \\
\text { methylcellulose } \\
\text { (mg) }\end{array}$ & & & \\
\hline B & $\begin{array}{l}\text { Carboxymethyl } \\
\text { cellulose sodium } \\
(\mathrm{mg})\end{array}$ & 30 & 50 & 70 \\
\hline $\mathrm{C}$ & $\begin{array}{l}\text { Hydroxypropyl } \\
\text { cellulose (mg) }\end{array}$ & 5 & 20 & 35 \\
\hline \multicolumn{2}{|c|}{ Responses } & Goal & \multicolumn{2}{|c|}{$\begin{array}{c}\text { Acceptable } \\
\text { ranges }\end{array}$} \\
\hline$Y_{1}$ & $\begin{array}{c}\text { Dissolution } 1 \mathrm{~h} \\
(\%)\end{array}$ & In range & \multicolumn{2}{|c|}{$20 \underset{1}{Y_{1} \leq 40}$} \\
\hline$Y_{2}$ & $\begin{array}{c}\text { Dissolution } 3 \mathrm{~h} \\
(\%)\end{array}$ & In range & \multicolumn{2}{|c|}{$\begin{array}{c}40 Y \leq 60 \\
2\end{array}$} \\
\hline$Y_{3}$ & $\begin{array}{c}\text { Dissolution } 8 \mathrm{~h} \\
(\%)\end{array}$ & Maximize & \multicolumn{2}{|c|}{$\geq 80$} \\
\hline
\end{tabular}

\section{Assay}

The assay was identified using method validation information for metformin and linagliptin tablets from the Ministry of Health and Population from the Government of Nepal. ${ }^{14}$

\section{Dissolution test}

The dissolution rates of tablets were evaluated in water (50 rpm; $900 \mathrm{~mL}$; time points: 15, 30, 45 and $60 \mathrm{~min}$ ) for linagliptin and at $\mathrm{pH} 6.8(100 \mathrm{rpm}$; $900 \mathrm{~mL}$; time points: 1,3 and $8 \mathrm{~h}$ ) for metformin using the basket method (USP apparatus 1). ${ }^{14}$

\section{Statistical analysis}

All statistical analyses were performed using a full factorial design using Design-Expert version 12.0.3.0 (Stat-Ease Inc., Minneapolis, MN, USA). The statistical parameters $P<0.05$, F test, coefficient of determination $\left(R^{2}\right)$ and adjusted coefficient of determination (adjusted $R^{2}$ ) were calculated.

\section{RESULTS}

\section{Effects on friability, dissolution and assay for linagliptin}

The experimental results for the factors and responses are shown in Table 3. The results for linagliptin showed that friability varied from $0.25 \%$ to $1.23 \%$, dissolution (f2) from 36.05 to 61.91 and assay from 97.73 to $102.33 \%$ (Table 3). All three independent factors were apparently affected by the quality attributes of friability (Figure 1A; half-normal plot). Among the selected factors, sodium starch glycolate was strongly affected by the quality attributes of dissolution (Figure 1C) and mannitol content was slightly affected by the quality attributes of the assay (Figure 1E). When mannitol and pregelatinized starch were increased, friability tended to decrease (Figure 1B; main effect plot). When sodium starch glycolate was increased, the similarity of dissolution tended to increase (Figure 1D). Mannitol, ranging from 40 to $50 \mathrm{mg}$, accommodated the assay (approximately 100\%) (Figure 1F). As shown in the analysis of variance (ANOVA) results in Table 5, for the CMAs, friability was the most significant $(P<0.05)$ response affected in all three independent factors. The most significant factors affecting dissolution and assay were sodium starch glycolate and mannitol. 


\section{Effects on dissolution for metformin}

The experimental results for the factors and responses are shown in Table 4. Metformin showed that dissolution (f2) varied from 26.50 to 35.91 (1 h), 48.12 to 64.69 (3 h) and 74.09 to 94.74 (8 h) (Table 4). Among selected factors, CMC and hydroxypropyl cellulose were strongly affected by the quality attributes of dissolution (1,3 and $8 \mathrm{~h}$ ) (Figure 2). As shown in the ANOVA results in Table 5 , for the CMAs, dissolution at 1 and $8 \mathrm{~h}$ was affected the most significantly in CMC and hydroxypropyl cellulose. However, in all three independent factors, the factor affected significantly was dissolution at $3 \mathrm{~h}$.

\section{DISCUSSION}

Linagliptin and metformin SR FDC tablets are filmcoated tablets and are manufactured by the following process: wet granulation, lubrication, compression and coating. Linagliptin and metformin SR FDC tablets were subjected to a wet granulation process using water to
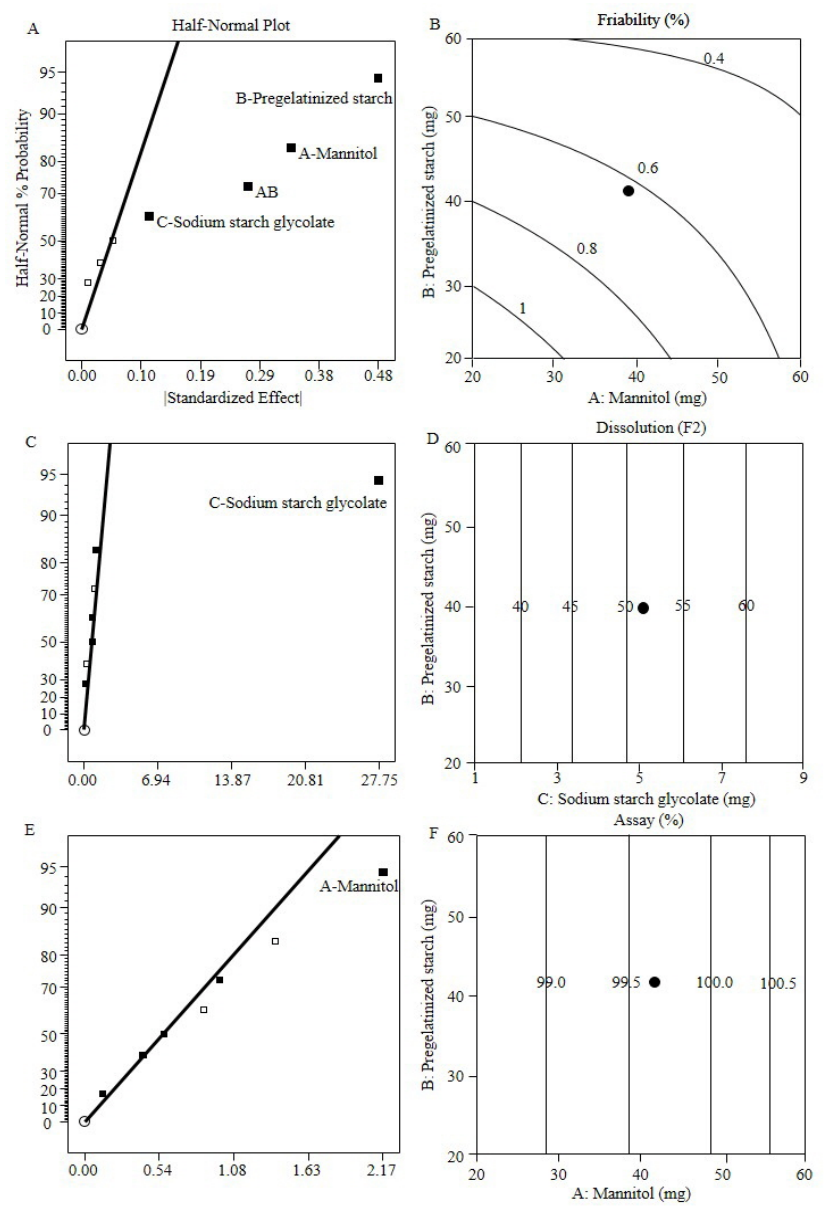

Figure 1: Half-normal plot and main effect of the material (additives) variable effects on friability (A and B), dissolution (C and D), and assay (E and F) for linagliptin layer. a Positive effect, $\Upsilon$ Negative effect, $\bullet$ Center point. obtain content uniformity and powder flowability. ${ }^{15}$ The DoE approach based on CQAs influenced by the quality target product profile of linagliptin and metformin SR FDC tablets was also established with reference to the RLDs (Trajenta ${ }^{\circledR} 5 \mathrm{mg}$ and Glucophage ${ }^{\circledR}$ XR 1000 $\mathrm{mg}) \cdot{ }^{11}$ Excipients are the most important source of process variability owing to their material functionality and physiochemical properties. ${ }^{16}$ For the CMAs DoE approach (0.4 kg lab-scale), all factors of wet granulation and tablet compression were performed using fixed values. The DoE study for CMAs was performed to identify the suitable range for excipients using mannitol, pregelatinized starch and sodium starch glycolate for linagliptin and hydroxypropyl methylcellulose, CMC and hydroxypropyl cellulose for metformin (Tables 1 and 2). The factors for CMAs constituted the focus of the DoE because the factors can affect the product CQAs of friability, assay and dissolution (Tables 1 and 2). The excipients of CMAs for the DoE study were selected based on opinions of a team member. ${ }^{17}$


Figure 2: Half-normal plot and main effect of the material (additives) variable effects on dissolution $1 \mathrm{~h} \mathrm{(A}$ and $B)$, dissolution $3 \mathrm{~h}$ (C and $D$ ), and dissolution $8 \mathrm{~h}$ ( $E$ and $F$ ) for metformin layer. - Positive effect, $\Upsilon \mathbf{r}$ Negative effect, $\bullet$ Center point. 
Table 3: Experimental results of the $2^{3}$ full factorial DoE to study CMA for linagliptin.

\begin{tabular}{|c|c|c|c|c|c|c|}
\hline \multicolumn{4}{|c|}{ Factors: Material attribute } & \multirow{2}{*}{$\begin{array}{c}\text { Responses } \\
Y_{1}: \\
\text { Friability }\end{array}$} & \multirow[b]{2}{*}{$\begin{array}{c}\mathrm{Y}_{2}: \\
\text { Dissolution }\end{array}$} & \multirow[b]{2}{*}{$\begin{array}{c}Y_{3}: \\
\text { Assay }\end{array}$} \\
\hline No. & $\begin{array}{c}\text { A: } \\
\text { Mannitol }\end{array}$ & $\begin{array}{c}\text { B: } \\
\begin{array}{c}\text { Pregelatinized } \\
\text { starch }\end{array}\end{array}$ & $\begin{array}{c}\text { C: } \\
\text { Sodium starch } \\
\text { glycolate }\end{array}$ & & & \\
\hline & (mg) & (mg) & (mg) & $(\%)$ & (F2) & $(\%)$ \\
\hline 1 & 60 & 20 & 1 & 0.54 & 36.05 & 102.33 \\
\hline 2 & 60 & 20 & 9 & 0.58 & 56.38 & 99.92 \\
\hline 3 & 20 & 60 & 9 & 0.46 & 57.72 & 99.85 \\
\hline 4 & 60 & 60 & 1 & 0.25 & 38.56 & 99.22 \\
\hline 5 & 20 & 60 & 1 & 0.38 & 36.87 & 98.33 \\
\hline 6 & 20 & 20 & 1 & 1.11 & 36.12 & 97.73 \\
\hline 7 & 40 & 40 & 5 & 0.44 & 61.76 & 100.92 \\
\hline 8 & 20 & 20 & 9 & 1.23 & 58.89 & 98.21 \\
\hline 9 & 40 & 40 & 5 & 0.46 & 61.33 & 99.87 \\
\hline 10 & 60 & 60 & 9 & 0.45 & 57.59 & 101.33 \\
\hline 11 & 40 & 40 & 5 & 0.47 & 61.91 & 101.38 \\
\hline
\end{tabular}

\section{Table 4: Experimental results of the $2^{3}$ full factorial DoE to study CMA for metformin.}

\begin{tabular}{|c|c|c|c|c|c|c|}
\hline \multicolumn{5}{|c|}{ Factors: Material attribute } & \multirow{2}{*}{$\begin{array}{c}\text { Responses } \\
\begin{array}{c}\mathrm{Y}_{2}: \\
\text { Dissolution } 3 \mathrm{~h}\end{array}\end{array}$} & \multirow[b]{2}{*}{$\begin{array}{c}\mathrm{Y}_{3}: \\
\text { Dissolution 8h }\end{array}$} \\
\hline No. & $\begin{array}{c}\text { A: } \\
\text { Hydroxypropyl } \\
\text { methylcellulose }\end{array}$ & $\begin{array}{c}\text { B: } \\
\text { Carboxymethyl } \\
\text { cellulose sodium }\end{array}$ & $\begin{array}{c}\text { C: } \\
\text { Hydroxypropyl } \\
\text { cellulose }\end{array}$ & $\begin{array}{c}\mathrm{Y}_{1}: \\
\text { Dissolution } 1 \mathrm{~h}\end{array}$ & & \\
\hline & (mg) & (mg) & (mg) & (\%) & (\%) & (\%) \\
\hline 1 & 220 & 30 & 5 & 34.55 & 57.44 & 88.19 \\
\hline 2 & 300 & 70 & 35 & 30.70 & 48.12 & 74.09 \\
\hline 3 & 300 & 30 & 35 & 33.60 & 51.65 & 83.96 \\
\hline 4 & 220 & 30 & 35 & 33.80 & 53.20 & 83.30 \\
\hline 5 & 260 & 50 & 20 & 26.50 & 50.90 & 85.70 \\
\hline 6 & 300 & 30 & 5 & 35.91 & 64.69 & 94.74 \\
\hline 7 & 260 & 50 & 20 & 27.60 & 51.10 & 85.90 \\
\hline 8 & 260 & 50 & 20 & 27.70 & 50.90 & 85.60 \\
\hline 9 & 300 & 70 & 5 & 33.30 & 60.78 & 88.75 \\
\hline 10 & 220 & 70 & 5 & 34.13 & 54.38 & 86.72 \\
\hline 11 & 220 & 70 & 35 & 30.80 & 49.50 & 78.30 \\
\hline
\end{tabular}

All results for the factors and responses are shown in Tables 3 and 4. The high risk of CMAs of linagliptin and metformin SR FDC tablets determined the selection of pregelatinized starch and sodium starch glycolate for the linagiptin layer and hydroxypropyl cellulose for the metformin layer affecting friability, assay and dissolution as CQAs (Figures 1 and 2). Among the three factors, for pregelatinized starch and mannitol, friability was an important quality attribute affected in the linagliptin layer (Figure 1A). The dissolution quality attribute was also importantly affected in sodium starch glycolate in the linagliptin layer (Figure 1C). The main effect plot (Figure 1B) indicated that when mannitol and pregelatinized starch content were increased by $>30 \mathrm{mg}$, 


\begin{tabular}{|c|c|c|c|c|c|c|}
\hline Source & $\begin{array}{c}\text { Sum of } \\
\text { squares }\end{array}$ & $d_{f}^{a}$ & $\begin{array}{l}\text { Mean } \\
\text { square }\end{array}$ & $F$-value & $\begin{array}{c}\text { p-value } \\
\text { (probe-F) }\end{array}$ & $\begin{array}{c}\text { Regression } \\
\text { coefficient }\end{array}$ \\
\hline \multicolumn{7}{|l|}{ Linagliptin } \\
\hline \multicolumn{7}{|l|}{ Friability } \\
\hline Model & 0.8620 & 1 & 0.2155 & 144.31 & $<0.0001$ & 0.9914 \\
\hline Lack of Fit & 0.0070 & 3 & 0.0023 & 10.00 & 0.0923 & - \\
\hline \multicolumn{7}{|l|}{ Dissolution } \\
\hline Model & 1539.57 & 1 & 1539.57 & 1658.22 & $<0.0001$ & 0.9952 \\
\hline Lack of Fit & 7.25 & 6 & 1.21 & 13.33 & 0.0714 & - \\
\hline \multicolumn{7}{|l|}{ Assay } \\
\hline Model & 9.42 & 1 & 9.42 & 7.87 & 0.0230 & 0.4958 \\
\hline Lack of Fit & 8.38 & 6 & 1.40 & 2.33 & 0.3303 & - \\
\hline \multicolumn{7}{|l|}{ Metformin } \\
\hline \multicolumn{7}{|l|}{ Dissolution $1 \mathrm{~h}$} \\
\hline Model & 20.07 & 2 & 10.04 & 21.88 & 0.0010 & 0.8621 \\
\hline Lack of Fit & 2.32 & 5 & 0.4648 & 1.05 & 0.5543 & - \\
\hline \multicolumn{7}{|l|}{ Dissolution $3 \mathrm{~h}$} \\
\hline Model & 225.49 & 4 & 56.37 & 1264.12 & $<0.0001$ & 0.9990 \\
\hline Lack of Fit & 0.1963 & 3 & 0.0654 & 4.91 & 0.1739 & - \\
\hline \multicolumn{7}{|l|}{ Dissolution $8 \mathrm{~h}$} \\
\hline Model & 250.02 & 2 & 125.01 & 22.15 & 0.0009 & 0.8636 \\
\hline Lack of Fit & 39.46 & 5 & 7.89 & 338.19 & 0.0830 & - \\
\hline
\end{tabular}
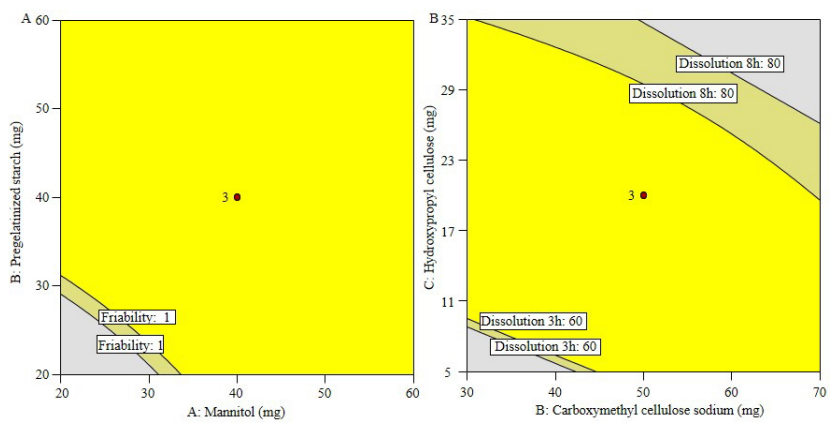

Figure 3: Design space for critical material attributes part of (A) Linagliptin layer at sodium starch glycolate $5 \mathrm{mg}$ and (B) metformin layer at hydroxypropyl methylcellulose $260 \mathrm{mg}$.

friability was found to decrease. The dissolution $(50<\mathrm{f} 2)$ also increased when the content of sodium starch glycolate was $>5 \mathrm{mg}$ (Figure 1D). The selected model (Table 5) indicated that mannitol and pregelatinized starch $(P \leq 0.0001)$ are the main effects for friability. However, the effect of sodium starch glycolate $(P=0.01)$ on dissolution was significantly less than $P<0.05$. Although mannitol $(P \leq 0.023)$ was affected on the assay, the level was low. In addition, the lack of fit for all values (friability, dissolution and assay) was not significant ( $P=0.0923,0.0714$ and 0.3303 , respectively) considering the pure error. ${ }^{18}$ The $p$-values $(P=0.0002)$ of the $\mathrm{AB}$ (mannitol and pregelatinized starch) interaction were remarkably less than 0.05 (Figure 1A). Mannitol and pregelatinized starch had a significant effect on friability and the interaction between them $(\mathrm{AB})$ was also a main factor. Friability and dissolution (f2) of batches 1, 5, 6 and 8 with mannitol $(20 \mathrm{mg})$ or pregelatinized starch $(20 \mathrm{mg})$ demonstrated unacceptable results (friability: 1.11-1.23 and dissolution f2: 36.05-38.56) based on the acceptance criteria (friability: $>1 \%$ and dissolution $\mathrm{f} 2>50$ ) (Table 3). Generally, the selection of diluents is very important in the wet granulation process as granule size and density affect the CQAs (dissolution, friability and disintegration time). ${ }^{19}$

Among the three factors, the effect on the quality attributes of dissolution for hydroxypropyl cellulose and $\mathrm{CMC}$ were important $(1,3$ and $8 \mathrm{~h}$ ) in the metformin layer (Figure 2A, 2C and 2E). The main effect plot (Figure $2 \mathrm{~B}$ and $2 \mathrm{~F}$ ) indicated that when hydroxypropyl cellulose and $\mathrm{CMC}$ increased, dissolution rates were found to have values close to $30 \%$ and $80 \%$, respectively. The value of dissolution was also $50 \%$ when the amount of hydroxypropyl methylcellulose and hydroxypropyl cellulose was approximately 260 and $30 \mathrm{mg}$, respectively (Figure 2D). The selected model (Table 5) indicated that hydroxypropyl cellulose and $\mathrm{CMC}$ are the main effects for dissolution rates of $30 \%(P=0.002)$ and $80 \%$ ( $P=0.001)$, respectively. However, three factors on $80 \%$ 
of dissolution rate is significantly affected $(P \leq 0.0001)$. All values for the lack of fit for dissolution were not significant $(P=0.4648,0.0654$ and 7.89 of dissolution 30 , 50 and $80 \%$ ) considering the pure error. The $P$-values $(P \leq 0.0001)$ of the AC (Hydroxypropyl methylcellulose and hydroxypropyl cellulose) interaction at the 50\% dissolution rate were remarkably less than 0.05 (Figure 2C). Hydroxypropyl methylcellulose and hydroxypropyl cellulose had a significant effect on dissolution and the interaction between them (AC) was also a main factor. The dissolution (f2) of batches 2 and 11 with hydroxypropyl cellulose (220 and $300 \mathrm{mg}$ ) demonstrated unacceptable results (dissolution $8 \mathrm{~h}: 74.09 \%$ and $78.30 \%$ ) based on the acceptance criteria (dissolution $8 \mathrm{~h}:>80 \%$ ) (Table 4). This result is not indicative of the amount of hydroxypropyl cellulose, but that of a difference in the dissolution rate according to the combination of hydroxypropyl methylcellulose and CMC.

The difference $(<0.2)$ and ratio $(>4)$ of predicted and adjusted regression coefficient $\left(R^{2}\right)$ should be identified based on the ANOVA results through analysis of the design space. ${ }^{20}$ The results obtained in this study showed the presence of a difference of $0.043,0.003$ and 0.041 and ratio of $32.586,55.137$ and 38.389 for the predicted and adjusted $R^{2}$ of friability, dissolution ( $f 2$ ) and assay, respectively, of linagliptin. Metformin also showed a difference of $0.164,0.005$ and 0.174 and ratio of $20.378,105.155$ and 10.660 for dissolution at 1,3 and 8 $\mathrm{h}$, respectively.

To confirm the composition of the material attributes, a design space with a 95\% confidence interval on the mean values of responses is shown in Figure 3. The design space was established as indicated in the region marked in yellow for the optimal ranges for the composition of material attributes. A tablet comprising mannitol $(40 \mathrm{mg})$, pregelatinized starch $(40 \mathrm{mg})$ and sodium starch glycolate $(5 \mathrm{mg})$ for the linagliptin layer and of hydroxypropyl cellulose (17 mg), CMC (50 mg) and hydroxypropyl methylcellulose $(260 \mathrm{mg}$ ) for the metformin layer would reach the desired minimized value for friability and the range of dissolutions and assay (Figure 3).

\section{CONCLUSION}

Based on the quality target product profile, the screening of material attributes for excipients was identified at the laboratory scale using the QbD approach. In the initial risk assessments, the high risks (mannitol, pregelatinized starch and sodium starch glycolate for linagliptin and hydroxypropyl cellulose, CMC and hydroxypropyl methylcellulose for metformin) were evaluated using the DoE study to identify their acceptance criteria for the amount of excipients. Each of the three factors for linagliptin and metformin were critical process parameters for the minimum value for friability and the desired range of dissolutions and assays. Accordingly, the ranges of the independent variables were well defined as mannitol (40-60 mg) and pregelatinized starch (40-60 $\mathrm{mg}$ ) with sodium starch glycolate $(5 \mathrm{mg})$ for linagliptin and hydroxypropyl cellulose (15-23 mg) and CMC (40$55 \mathrm{mg}$ ) with hydroxypropyl methylcellulose $(260 \mathrm{mg})$ for metformin that had no significant effect on friability, assay and dissolution. This study concluded that the determined amount of each excipient can be used for formulating linagliptin and metformin SR FDC tablets.

\section{ACKNOWLEDGEMENT}

This research was supported by a Kyungsung University Research Grants in 2021.

\section{CONFLICT OF INTEREST}

The author declare no conflict of interest.

\section{ABBREVIATIONS}

SR: Sustained Release; FDC: Fixed-dose Combination; DoE: Design of Experiments; CMC: Sodium Carboxymethyl Cellulose; RLD: Reference Listed Drug; $\mathbf{C}_{\max }$ : The Maximum Plasma Concentration; CQAs: The critical Quality Attributes; QbD: The Quality by Design; CMAs: Critical Material Attributes; ANOVA: The Analysis of Variance.

\section{REFERENCES}

1. Freeman MK. Efficacy and safety of linagliptin (Tradjenta) in adults with type2 diabetes mellitus. Pharmacy and Therapeutics. 2011;36(12):807-12.

2. Websky VK, Reichetzeder C, Hocher B. Linagliptin as add-on therapy to insulin for patients with type 2 diabetes. Vascular Health Risk Management. 2013;9(1):681-94. https://doi.org/10.2147/VHRM.S40035.

3. Lauand F, Hohl A, Ronsoni MF, Guedes EP, Melo DTG. Linagliptin: DPP-4 inhibition in the treatment of type 2 diabetes mellitus. Journal of Diabetes and Metabolic Disorders. 2014;1(1):13-9. https://doi.org/10.3810/ pgm.2011.07.2303.

4. Gu NY, Park SI, Chung HW, Jin XY, Lee SH, Kim TE. Possibility of pharmacokinetic drug interaction between a DPP-4 inhibitor and a SGLT2 inhibitor. Translational Clinical Pharmacology. 2020;28(1):17-33. https://doi. org/10.12793/tcp.2020.28.e4.

5. Rojas A, Gomes MB. Metformin: An old but still the best treatment for type 2 diabetes. Diabetology and Metabolic Syndrome. 2013;5(1):6. https://doi. org/10.1186/1758-5996-5-6.

6. Dumitrescu R, Mehedintu C, Briceag I, Purcărea VL, Hudita D. Metforminclinical pharmacology in PCOs. Journal of Medicine and Life. 2015;8(2):18792.

7. Friedrich C, Brand T, Ring A, Meinicke T. Bioequivalence of glucophage ${ }^{\circledR}$ (Metformin) tablets from europe and the united states tested in healthy 
volunteers. Journal of Bioequivalence and Bioavailability. 2014;6(2):61-6. https://doi.org/10.4172/jbb.1000181.

8. Dunn CJ, Peters DH. Metformin. A review of its pharmacological properties and therapeutic use in non-insulin-dependent diabetes mellitus. Drugs. 1995;49(5):721-49. https://doi.org/10.2165/00003495-199549050-00007.

9. Rathore AS. Roadmap for implementation of quality by design (QbD) for biotechnology products. Trends in Biotechnology. 2009;27(2):546-53. https:// doi.org/10.1016/j.tibtech.200 -9.06.006.

10. Rathore AS, Winkle H. Quality by design for biopharmaceuticals. Nature Biotechnology. 2009;27(1):26-34. https://doi.org/10.1038/nbt0109-26.

11. ICH Harmonized Tripartite guideline- Pharmaceutical development Q8(R2). Current step 4. 2009.

12. Gray V. Power of the dissolution test in distinguishing a change in dosage form critical quality attributes. AAPS PharmSciTech. 2018;19(8):3328-32. https://doi.org/10.1208/s12249-018-1197-7.

13. United States Pharmacopoeia and Formulary (USP 41/ NF 36) Rockville, MD, United States Pharmacopoeia Convention. 2018;7634-5.

14. Government of Nepal. Department of drug administration: Ministry of Health and Population. 2020. [updated 2019 Nov 7; cited 2020 Jan 7]. Available from: http://www.dda.gov.np/content/method-validation.
15. Shanmugam S. Granulation techniques and technologies: Recent progresses. Bioimpacts. 2015;5(1):55-63. https://doi.org/10.15171/bi.2015.04

16. Product Quality Research Institute (PQRI). Process robustness-APQRI white paper. Pharmaceutical Engineering. 2006;26:1.

17. Yu LX. Pharmaceutical quality by design: Product and process development, understanding and control. Pharmaceutical Research. 2008;25(4):781-91. https://doi.org/10.1007/s11095-007-9511-1.

18. Akala EO, Adesina S, Ogunwuyi O. Computer optimization of biodegradable nanoparticles fabricated by dispersion polymerization. International Journal of Environmental Research and Public Health. 2016;13(1):47. https://doi. org/10.3390/ijerph13010047.

19. Lee AR, Kwon SY, Choi DH, Park ES. Quality by Design (QbD) approach to optimize the formulation of a bilayer combination tablet (Telmiduo ${ }^{\circledR}$ ) manufactured via high shear wet granulation. International Journal of Pharmaceutics. 2017;534(1-2):144-58. https://doi.org/10.1016/j. ijpharm.2017.10.004.

20. Nkuzinna OC, Menkiti MC, Onukwuli OD, Mbah GO, Okolo BI, Egbujor MC, et al. Application of factorial design of experiment for optimization of inhibition effect of acid extract of Gnetum africana on copper corrosion. Natural Resources. 2014;5(7):299-307. http://dx.doi.org/10.4236/nr.2014.57028.

\section{PICTORIAL ABSTRACT}

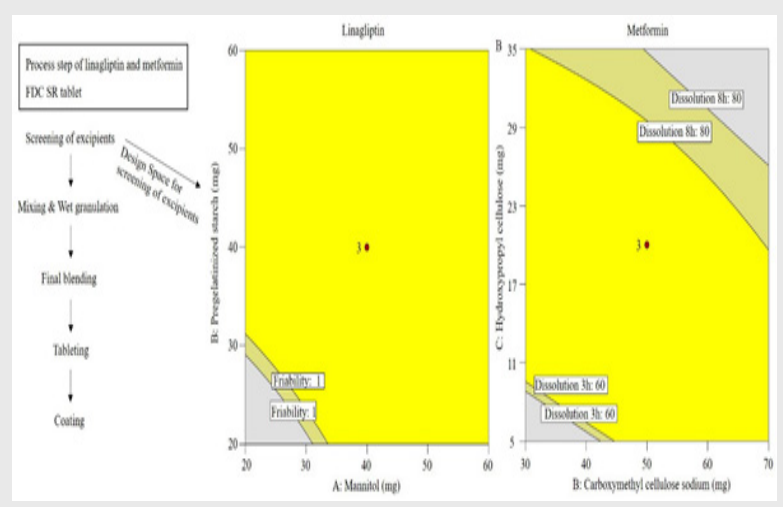

\section{SUMMARY}

- Linaglptin and metformin SR FDC tablet was investigated the ranges of excipients for drug product through design of experiments.

- Mannitol (40-60 mg) and pregelatinized starch (40-60 mg) with sodium starch glycolate $(5 \mathrm{mg}$ ) for linagliptin and hydroxypropyl cellulose (15$23 \mathrm{mg}$ ) and CMC (40-55 mg) with hydroxypropyl methylcellulose $(260 \mathrm{mg})$ for metformin were optimal ranges for drug product.

- The identification of the wide ranges for excipients will produce high quality products.



Cite this article: Kim KM. Design of Experiments for Critical Material Attributes Assessment of Linagliptin and Metformin Fixed-dose Combination Tablets. Indian $\mathrm{J}$ of Pharmaceutical Education and Research. $2021 ; 55(3): 701-8$. 